\title{
El éxito del fracaso escolar
}

\author{
Francisco Arenas Ferriz:
}

Cuando hablamos de los problemas de la enseñanza viene a nuestra mente en primer lugar, y sin competencia posible, la idea de fracaso escolar. Este es el concepto que parece describir, mejor que cualquier otro, la situación de la enseñanza en el mundo.

Según los análisis más comunes el proceso educativo se desarrolla de un modo caótico e infructuoso debido a la confluencia de multitud de conflictos irresolutos en el mismo: tradición y modernidad, humanidades y tecnologías, anacrónica preparación profesional y exigencias de aggiornamento, masificación y enseñanza personalizada, retórica de la importancia social de la enseñanza pero paulatina pérdida de dignidad del trabajo de los enseñantes.

No voy a negar la existencia de todos estos fenómenos, pero no deseo compartir la fatalista y milagrera actitud que caracteriza buena parte de los análisis a que antes me refería. Suelen constar estos de un primer momento de 
lloros y lamentaciones ante el invencible fracaso, y un segundo momento en el que se propone un mágico remedio consistente, habitualmente, en alguna de estas fórmulas: técnicas de estudio para el alumno, didáctica para el profesor, reciclaje con retitulación y creación de un nuevo organismo, generalmente encadenadas en este mismo orden. Como no solucionan nada, deben presentarse cada vez con un envoltorio diferente cual si de remedios contra la calvicie se tratase. La confianza en el remedio futuro nos alivia de la inutilidad del anterior.

La verdad es que si la sociedad no se defiende efectivamente del fracaso escolar es porque le resulta consustancial, de la misma manera que los denostados hábitos consumistas son el eje básico de la economía mercantilista.

La función básica del proceso educativo (entenderemos la enseñanza como la sistematización social de los diferentes comportamientos educativos) es la de reproducir el mundo de los adultos en los hábitos y conciencia de niños y adolescentes, preparando, así, su ingreso en aquel. La sociedad tiene, de este modo, garantizada su supervivencia por la función reproductora de la escuela.

En tiempos revolucionarios, la escuela es, asimismo, el instrumento fundamental que garantiza la asimilación social de las transformaciones llevadas a cabo por las élites dirigentes. La escuela normaliza definitivamente los procesos de cambio al dar forma de norma a las novedades, revolucionarias. Sin menoscabo de los propósitos reformistas de cualquier plan de estudios o proyecto global, las estructuras esenciales del cuerpo social se perpetúan en y gracias a la escuela.

Así pues, sólo en el caso de que este objetivo fundamental no se cumpla, sólo si la sociedad adulta no logra reproducir sus hábitos, ideas y concepciones 
en el mundo de los escolares, cabría hablar de fracaso escolar, de incumplimiento de objetivos. Y... es ¿esto lo que ocurre?

No resulta difícil comprobar el modo como tales funciones, antes que fracasar, se realizan. En nuestra sociedad de consumo los seres humanos se ajustan al esquema productor-consumidor. La vinculación entre consumidor y objeto a consumir esta mediatizada, decisivamente, por el precio del objeto; y la relación entre producto a producir y productor por el salario o precio del obrero. En ambos casos el dinero es el eje sobre el que tal relación gira de tal manera que siempre consiste en un acto de compraventa, en un acto de mercadería. Todo es, en definitiva, mercancía. (Ya no es necio aquí quien confunde valor y precio, sino quien diferencia tales cosas). La escuela no puede sustraerse, naturalmente, a este proceso general de mercantilización. El saber, lo enseñable, es hoy mercancía privilegiada, objeto de consumo materializado ejemplarmente no sólo en multitud de libros de texto hechos no para ser leídos, sino para ser simplemente, vendidos, sino en muchos otros aspectos de la vida escolar. Las enciclopedias escolares de antaño, utilizadas por padres e hijos año tras año, han sido sustituidas por libros-objeto "no return" que se desechan sin apenas rendimiento y que es preciso adquirir en cada curso.

La calificación es un salario y la discusión sobre el trabajo escolar se limita, a la pugna por conseguir un salario-nota más elevado, independientemente de cual sea la calidad del producto final; así, el profesor problemático no es el que enseña poco o mucho, sino el que pagacalifica bajo. Las mejores calificaciones son aquellas que tienen tanto detalle como la nómina de un funcionario y las pruebas de suficiencia se denominan en el argot de los enseñantes rebajas. Los exámenes parciales son ventas a plazos, las recuperaciones letras de cambio caducadas, la evaluación final un balance de gastos y beneficios plena, obsesivamente, de porcentajes, y el alumno un 
número que se valora numéricamente. El alumno elige asignaturas como si jugase a la Bolsa y los profesores justifican la baja rentabilidad de su inversión por el desinterés habitual del alumno-capital. Los méritos se llaman créditos y la acumulación de años-antigüedad es más valorada que la calidad del trabajo realizado. La escuela, pues, reproduce y perpetúa esta esencial estructura social consumista y financiera perfectamente. Otros rasgos de la sociedad, derivados de su carácter mercantilista, aparecen también en la vida escolar: insatisfacción ante el trabajo realizado, individualismo, búsqueda del beneficio privado, insolidaridad, incomunicación, necesidad de sustitutivos más placenteros, trabajo enajenado, en definitiva.

Los jóvenes finalizan su período escolar convertidos en ávidos y sumisos consumidores, acríticos acomodados al sistema establecido, habituados a superar etapas por medio de trámites burocráticos y convencidos de que el poder es algo lejano de lo que sólo cabe esperar arbitrariedades y de que el trabajo intelectual no es nunca un fin en sí mismo, ni tampoco un acto de servicio social, sino sólo un incómodo medio para la supervivencia individual.

La escuela, en efecto, no fracasa. El fracaso corresponde, en todo caso, a la sociedad de la que forma parte y cuyos valores transmite fielmente. Sólo quien entienda la solidaridad desinteresada, la poesía gratuita, la filosofía inútil, la ciencia no tecnologizada o el ocio creativo como valores en sí mismos, puede sentirse desengañado por el funcionamiento de la escuela. 